\title{
Varied Presentation of Pheochromocytoma: Surgical and Anesthetic Management of Three Different Cases
}

\author{
Anusha R Musti ${ }^{1}$, Kailash Prakash², Kallur T Venkateshmurthy ${ }^{3}$
}

\begin{abstract}
Pheochromocytoma, the neuroendocrine tumors arising from chromaffin tissue, poses a very significant challenge to the anesthetists, especially when they are undiagnosed. They present with varied symptoms and sometimes they are silent and nonfunctional. The anesthetic management of these tumor excisions varies depending on the surgical approach and perioperative hemodynamic instability encountered by the anesthetist. Here, we are presenting three different cases of pheochromocytoma who underwent adrenalectomy in our hospital with varied presentation and their successful anesthetic management.

Keywords: Anesthetic management, Pheochromocytoma, Varied presentation.

The Journal of Medical Sciences (2019): 10.5005/jp-journals-10045-00117
\end{abstract}

\section{INTRODUCTION}

Pheochromocytomas are rare endocrine tumors arising from the chromaffin tissue with a prevalence rate of $0.2-0.6 \%$ in patients with hypertension. The prevalence of extra-adrenal tumors, also called as paragangliomas, with germline mutations may be as high as 50\%. ${ }^{1,2}$ They present a more complex and life-threatening situation when undiagnosed and may precipitate a hypertensive crisis with a mortality rate of up to $80 \%{ }^{2,3}$ Thorough preoperative evaluation and preparation of these patients is key to successful perioperative management.

Observation of Roizen criteria, proposed by Roizen and others in 1982, to gauge the efficacy of adequate preoperative alpha blockade includes

- No in-hospital blood pressure (BP) $>160 / 90$ mm Hg. For 24 hours, prior to surgery

- No orthostatic hypotension with BP $<80 / 45 \mathrm{~mm} \mathrm{Hg}$

- No more than 5 premature ventricular ectopics/minutes.

Alpha-adrenergic blockade is an absolute necessity before starting beta-blockade while preparing these patients for surgery. ${ }^{4,5}$

Though some institutions use a combination of alphaadrenergic blockade, beta-adrenergic blockade, and calcium channel blockers routinely, it is advisable to start with alphaadrenergic blockade using intravenous phenoxybenzamine $10 \mathrm{mg}$ twice daily to a maximum of $1 \mathrm{mg} / \mathrm{kg} /$ day with hospital admission and continuous medical supervision for 10-14 days. After obtaining an adequate length of alpha-adrenergic blockade (normalization of BP with mild orthostatic hypotension), beta-adrenergic blockade should be started to make the patient hemodynamically stable before posting for surgery. ${ }^{6-10}$

Apart from phenoxybenzamine, other short-acting alpha blockers, like prazosin (2-5 mg 2-3 times/day), terazosin (2-8 $\mathrm{mg} /$ day), and doxazosin (2-5 mg/day), are also used for immediate control of BP. ${ }^{9}$

The use of dihydropyridine calcium channel blockers in the perioperative period remains useful because they are short acting, easily titratable. They inhibit norepinephrine-induced $\mathrm{Ca}^{+}$ influx causing relaxation of the vascular smooth muscle and, thus, vasodilatation.

\footnotetext{
${ }^{1-3}$ Department of Anaesthesiology, RajaRajeswari Medical College and Hospital, Bengaluru, Karnataka, India
}

Corresponding Author: Kailash Prakash, Department of Anaesthesiology, RajaRajeswari Medical College and Hospital, Bengaluru, Karnataka, India, Phone: +91 8892224006, e-mail: kailashprakash@ outlook.com

How to cite this article: Musti AR, Prakash K, et al. Varied Presentation of Pheochromocytoma: Surgical and Anesthetic Management of Three Different Cases. J Med Sci 2019;5(2):51-56.

Source of support: Nil

Conflict of interest: None

Nicardipine, a potent arterial vasodilator, may be started perioperatively at the rate of 3-5 mg/hour for 15 minutes and adjusted by increments of $0.5 \mathrm{mg} /$ hour every 15 minutes. It is a safe drug, causing no tachycardia but can result in persistent hypotension due to its prolonged elimination half-life (40-60 minutes).

Selective beta 1 blockers like atenolol or metoprolol are recommended after complete alpha-adrenergic blockade to control tachycardia secondary to alpha blockade. Esmolol, beta 1-adrenergic blocker with rapid onset and short duration of action, makes it an ideal drug to suppress the intubation response while administering $\mathrm{GA}$.

Magnesium sulfate $\left(\mathrm{MgSO}_{4}\right)$, a membrane stabilizer, inhibits adrenal catechol release and decreases alpha-adrenal receptor sensitivity to catecholamine. It is a predominant arteriolar dilator, decreases left ventricular after load, and maintains preload. ${ }^{11}$

Sodium nitroprusside (SNP) and glycerol trinitrate (NTG), the NO donors, with SNP being a predominant arterial dilator and NTG a venodilator and both having rapid onset and offset of action, are the main drugs used to control intraoperative surge in $\mathrm{BP}{ }^{8}$

Hypotension after tumor devascularization/excision (due to residual alpha blockade and abrupt catechol deficiency) can be managed with a combination of fluid boluses, titration/ discontinuation of vasodilators, and administration of vasoconstrictors/alpha-adrenergic agonists. ${ }^{12}$

Noradrenaline at the rate of $0.2-3 \mu \mathrm{g} / \mathrm{kg} /$ minute or adrenaline at the rate of $0.01-0.05 \mu \mathrm{g} / \mathrm{kg} / \mathrm{minute}$ or vasopressin at the rate of

() The Author(s). 2019 Open Access This article is distributed under the terms of the Creative Commons Attribution 4.0 International License (https://creativecommons. org/licenses/by-nc/4.0/), which permits unrestricted use, distribution, and non-commercial reproduction in any medium, provided you give appropriate credit to the original author(s) and the source, provide a link to the Creative Commons license, and indicate if changes were made. The Creative Commons Public Domain Dedication waiver (http://creativecommons.org/publicdomain/zero/1.0/) applies to the data made available in this article, unless otherwise stated. 
0.4-20 units bolus doses or $1-3$ units $/ \mathrm{kg} /$ minute infusion are the drugs used to maintain BP after the excision of the tumor. The dose of these drugs is adjusted according to the intensity of hypotension and its response to the drug used. In the case of severe hypotension, more than one drug can be started to stabilize the BP.

Hydrocortisone at the rate of $100 \mathrm{mg}$ boluses 8 th hourly postoperatively should be started to replenish acute fall in cortisol after tumor excision, weaned gradually to $25 \mathrm{mg}$ twice daily in the next 72 hours, and then changed to oral prednisolone as replacement therapy.

Here, we are presenting three different cases of pheochromocytoma who underwent successful excision in our hospital and the way they were managed in the perioperative period.

\section{Case Description}

\section{Case 1}

A female patient aged 39 years came to surgical outpatient department (OPD) complaining of vague pain in the right side of the abdomen since 4 weeks. It was dull aching in nature, gradual in onset, and not radiating or relieving with any medication. It was not associated with vomiting, loose motion, or loss of appetite. She was experiencing general weakness for the last 10 days. No significant family history. On examination and radiological investigations, she was found to have a right-sided adrenal mass measuring $7.7 \times 7 \times$ $7 \mathrm{~cm}$ with a mixed (solid and cystic) consistency.

She was referred to urology for further management. She was diagnosed to have a nonfunctioning right-sided adrenal tumor adjacent to the right kidney and planned for open adrenalectomy.

Her preoperative evaluation showed that she was an adult female weighing $60 \mathrm{~kg}$ with a body mass index (BMI) of 25.96; American Society of Anesthesiologist (ASA) grade II; Mallampati grade l; not anemic; with $\mathrm{Hb} 11.8 \mathrm{~g} / \mathrm{dL}$; complete blood count (CBC), liver function test (LFT), renal function test (RFT), electrolytes, and blood glucose were within normal limits; heart rate (HR) 88/minute; BP 150/90 mm Hg. Serum catecholamine, vanillylmandelic acid (VMA), and urinary metanephrine were within normal limits. No comorbidities. She was accepted for surgery under general anesthesia with endotracheal intubation and epidural anesthesia for postoperative pain management.

After explaining the anesthetic plan and risk and also the surgical procedure to the patient and her attenders, a written consent was taken.

The sixth hourly BP chart was maintained and monitored for 3 days before the day of surgery, which showed BP variation between 130/90 and 150/100 $\mathrm{mm} \mathrm{Hg}$ and the HR was between 76 and 92 beats/minute on all these occasions. Since there was no gross variation in the BP in the preoperative period, alpha or beta blockers were not advised preoperatively.

The patient was kept nil orally from $10 \mathrm{pm}$ the day before the surgery. Tab. alprazolam $2.5 \mathrm{mg}$ was given in the night before the surgery. Inj. ranatidine150 $\mathrm{mg}$ and inj. ondansetron $4 \mathrm{mg}$ were given IV in the morning before shifting to the operation theater (OT).

On the day of the surgery, the OT was kept ready with all the inotropes and other cardiac drugs along with defibrillator. Four IV infusion sets were kept ready with inj. SNP, glycerin trinitrate, norepinephrine, epinephrine diluted, and ready for use.

After shifting to the OT, she was secured with two IV cannulas, $16 \mathrm{G}$ and $18 \mathrm{G}$, one on each of the upper limbs. Right dorsalis pedis artery and internal jugular vein (IJV) were cannulated and secured for beat to beat monitoring of $\mathrm{BP}$ and central venous pressure monitoring, respectively. Noninvasive BP (NIBP) cuff was applied on the left calf muscle. An epidural catheter $(18 \mathrm{G})$ was passed under full aseptic precaution in the T11-T12 spinal space for postoperative analgesia and secured.

She was premedicated with inj. midazolam $1 \mathrm{mg}$ IV and inj. fentanyl 2 micrograms/kg IV Inj. Glycopyrrolate was exempted in view of suspected tachycardia occurring during surgery. She was also induced with inj. propofol $2 \mathrm{mg} / \mathrm{kg}$ slow IV after preoxygenation for full 3 minutes. She was intubated with no. 7.5 cuffed endotracheal tube (ET) using inj. vecuronium $0.1 \mathrm{mg} / \mathrm{kg}$ and inj. loxicard $0.5 \mathrm{mg} / \mathrm{kg}$. During laryngoscopy and intubation, BP varied between $130 / 90$ and $160 / 100 \mathrm{~mm} \mathrm{Hg}$, and the HR remained between 78 and 86 . She was maintained with incremental doses of vecuronium $1 \mathrm{mg}+$ isoflurane $1 \mathrm{mac}+$ oxygen $3 \mathrm{~L} /$ minute and $\mathrm{N}_{2} \mathrm{O}$ at $5 \mathrm{~L} /$ minute throughout the procedure.

A gradual increase in BP from 140/90 to $180 / 120 \mathrm{~mm} \mathrm{Hg}$ was noted when the surgeon was manipulating the tumor. A bolus dose of NTG $4 \mu \mathrm{g}$ was given to control BP. Later, it remained between $110 / 60 \mathrm{~mm} \mathrm{Hg}$ and 120/76 mm Hg. No tachycardia noted. After ligating the vessels supplying and draining the tumor, a sudden drop in BP to $80 / 50 \mathrm{~mm} \mathrm{Hg}$ was noted which was treated with transfusion of normal saline $1.5 \mathrm{~L}$ in 30 minutes to fill the vessels and no inotropes or vasopressors were used. BP was maintained at 110/70-130/70 mm $\mathrm{Hg}$ throughout the procedure. Central venous pressure (CVP) was maintained between $11 \mathrm{~cm}$ of $\mathrm{H}_{2} \mathrm{O}$ and $14 \mathrm{~cm}$ of $\mathrm{H}_{2} \mathrm{O}$.

Thirty minutes before the end of the surgery, epidural was activated with $10 \mathrm{~mL}$ of inj. bupivacaine $0.25 \%$ for postoperative analgesia, and $100 \mathrm{mg}$ of inj. hydrocortisone was given slowly as bolus replacement of cortisol.

At the end of the surgery, the residual neuromuscular blockade (90\% twitch recovery) was reversed with inj. neostigmine $2.5 \mathrm{mg}$ + inj. glycopyrrolate $0.4 \mathrm{mg}$. She was extubated after complete recovery of consciousness and adequate spontaneous ventilatory efforts were obtained ( $>95 \% \mathrm{SpO}_{2}$ on room air). She was shifted to surgical intensive care unit (SICU) for further monitoring.

The total amount of blood loss was $200 \mathrm{~mL} ; 1.5 \mathrm{~L}$ of Ringer's lactate (RL), $1.5 \mathrm{~L}$ of normal saline, and $0.5 \mathrm{~L}$ of dextrose normal saline (DNS) were transfused throughout the surgery. The urine output was noted to be $650 \mathrm{~mL}$. The duration of the surgery was 2 hours and 20 minutes.

Postoperatively, all the vitals remained stable with BP varying from $100 / 60$ to $130 / 70 \mathrm{~mm} \mathrm{Hg}$. Epidural catheter was removed on the third postoperative day. She was shifted to the surgical ward for further management.

The histopathological examination of the excised tumor confirmed as pheochromocytoma.

\section{Case 2}

A 28-year-old female patient with a history of pain in the left lumbar region, headache, giddiness, and occasional palpitations since 1.5 months. She was a known case of hypertension since 6 years, on tab. telmisartan $40 \mathrm{mg}$ OD and tab. Lasix $10 \mathrm{mg}$ twice a week. She was also hypothyroid since 5 years-on tab.thyronorm $150 \mu \mathrm{g}$ OD. On CT scan, she was found to have a well-defined retroperitoneal solid mass adherent to the body of the pancreas adjacent to the left renal vessels. She was suspected to have a leftsided extra-adrenal tumor (paraganglioma) and referred to urology for further evaluation and management.

On evaluation, her 24-hour urine metanephrine and VMA levels were high (48.6/24 hours) (normal-13.9), and the serum 
cortisol level was on the higher side ( $28 \mu \mathrm{g}$, measured early in the morning) (normal $10-20 \mathrm{mcg}$ in the morning, 3-6 $\mu \mathrm{g}$ in the noon, and $<5 \mu \mathrm{g}$ in the night after fallen into sleep). BP varied from $146 / 100$ to $180 / 110 \mathrm{~mm} \mathrm{Hg}$. The fasting blood sugar was $164 \mathrm{mg} / \mathrm{dL}$; postprandial blood sugar (PPBS) was $286 \mathrm{mg} / \mathrm{dL}$; HbA1c was 8.6. All the other investigations were within normal limits. She was diagnosed to be suffering from the left-sided paraganglioma and was posted for tumor excision.

On preanesthetic evaluation, her weight was $78 \mathrm{~kg}$ with a height of $108 \mathrm{~cm}$ and a BMI of 29 . She had short neck and the Mallampati score of 2 . Her BP was 186/110 mm Hg with an HR of 100/minute. An endocrinologist's opinion was taken and all her antihypertensive medications were stopped. She was put on tab. phenoxybenzamine $10 \mathrm{mg}$ tid and Human actrapid insulin as per the sliding scale. Her BP and general random blood sugar (GRBS) were monitored 6th hourly for 1 week and the dose of phenoxybenzamine and insulin was adjusted accordingly to maintain stable BP of 130/90-150/90 $\mathrm{mm} \mathrm{Hg}$ and GRBS of $<180 \mathrm{~mm} \mathrm{Hg}$. Beta-blockers were kept in reserve for use in case if any tachycardia and hypertension occur.

She was advised not to take orally anything [nill per oral (NPO)] for 6 hours before surgery. Tab alprazolam $2.5 \mathrm{mg}$ was given the night before the surgery. Inj. ranitidine $150 \mathrm{mg}$ and inj. ondansetron $4 \mathrm{mg}$ along with tab. Thyronorm $150 \mu \mathrm{g}$ were given on the morning of surgery with advice to skip the morning dose of insulin. Her BP and $\mathrm{HR}$ were monitored from the previous day without disturbing her sleep (Table 1).

In the OT, the patient's BP was $162 / 90 \mathrm{~mm} \mathrm{Hg}$, HR was 90/ minutes, FBS was $160 \mathrm{mg} / \mathrm{dL}$, and serum electrolytes were within normal limits.

\section{Anesthetic Management}

On the day of surgery, the OT was kept ready, the workstation was checked, all the necessary drugs including inotropes, vasopressors (SNP, nitroglycerine (NTG), adrenaline, and noradrenaline) were diluted, loaded, and kept ready for infusion when needed.

Consent for anesthesia was taken from the patient and her attender after explaining the procedure and risk of anesthesia and surgery.

In the operation theater (OT), she was attached with NIBP, with a cuff on the left lower limb; electrocardiogram (ECG), pulse oxymeter, and two wide bore cannulas (18 G) were secured, one on each upper arm. The bladder was catheterized. The right radial artery was cannulated with $20 \mathrm{G}$ cannula for invasive BP monitoring.

As the patient's BP was high $(190 / 110 \mathrm{~mm} \mathrm{Hg})$ with an HR of $120 /$ minute, inj. esmolol $50 \mathrm{mg}$ in $100 \mathrm{~mL}$ of normal saline was started as slow IV infusion. She was preoxygenated with $100 \%$ oxygen for 5 minutes. She was premedicated with inj. midazolam $2 \mathrm{mg}$ and inj. fentanyl $100 \mu \mathrm{g}$ slow IV induced with inj. propofol

Table 1: Monitoring of patient a day before

\begin{tabular}{lll}
\hline Time & $B P(\mathrm{~mm} \mathrm{Hg})$ & $H R(\mathrm{bpm})$ \\
\hline 4 PM (day before surgery) & $170 / 110$ & 95 \\
6 PM (day before surgery) & $166 / 100$ & 96 \\
8 PM (day before surgery) & $160 / 100$ & 95 \\
12 AM (day before surgery) & $156 / 100$ & 94 \\
4 AM (day of surgery) & $140 / 100$ & 90 \\
6 AM (day of surgery) & $156 / 100$ & 90 \\
8 AM (day of surgery) & $148 / 94$ & 90 \\
9 AM (day of surgery) & $160 / 100$ & 93 \\
\hline
\end{tabular}

$130 \mathrm{mg}$ in incremental doses, and intubated using inj. vecuronium $6 \mathrm{mg}$, sevoflurane $2 \%$, and no. 7.0 cuffed endotracheal tube. Bilateral air entry was checked and the tube was fixed at $19 \mathrm{~cm}$. As the BP shoot up to 220/120, inj. SNP was started at $4 \mathrm{~mL} /$ hour. After 10 minutes, BP became stable at 130/95-140/100 $\mathrm{mm} \mathrm{Hg}$ with the HR at $90-100 /$ minute. Inj. esmolol and SNP were stopped. She was maintained with intermittent doses of vecuronium $1 \mathrm{mg}$, oxygen + nitrous oxide + isoflurane (1\%). Patient's right subclavian vein was cannulated and secured. She was turned to the right lateral position and the epidural catheter was passed in the T9-T10 space and secured at $9 \mathrm{~cm}$. The surgery was allowed to start in the same position with all additional precaution. Inj. paracetamol $1 \mathrm{~g}$ was given IV as a multimodal analgesic. Five minutes later, BP started to shoot up to $180 / 100 \mathrm{~mm} \mathrm{Hg}$, with an HR of $90 /$ minute. SNP was restarted at $5 \mathrm{~mL} / \mathrm{minute}$, isoflurane was increased to $1.5 \%$, inj. $\mathrm{MgSO}_{4} 1 \mathrm{~g}$ in $100 \mathrm{~mL}$ of NS was started slowly to maintain its membrane stability effect.

When the surgeons started manipulating around the tumor, BP suddenly started to shoot up to $233 / 123 \mathrm{~mm} \mathrm{Hg}$ with an HR of 112/minute (Fig. 1). SNP along with NTG was started at the rate of $5 \mathrm{~mL} /$ hour and $3 \mathrm{~mL} /$ hour respectively. Slowly BP started to come down to $168 / 103 \mathrm{~mm} \mathrm{Hg}$. When the tumor was ligated and removed (Fig. 2), BP suddenly dropped to $56 / 35 \mathrm{~mm} \mathrm{Hg}$ with an HR of 144/minute. Immediately both SNP and NTG were stopped, and noradrenaline $4 \mathrm{mg} /$ hour along with intermittent boluses of phenylephrine $30 \mu \mathrm{g}$ each was given to stabilize the BP at $148 / 86 \mathrm{~mm} \mathrm{Hg}$ with a HR of $88 /$ minute. Isoflurane was reduced to $0.5 \mathrm{MAC}$. Inj. hydrocortisone $100 \mathrm{mg}$ and inj. dexamethasone $8 \mathrm{mg}$ were given as cortisone replacement therapy and inj. fentanyl $50 \mu \mathrm{g}$ slow IV was given as additional analgesic.

Patient's blood sugar was checked and found to be $36 \mathrm{mg} / \mathrm{dL}$. Corrected with 25\% dextrose and maintained with 5\% DNS. Inj. noradrenaline was titrated throughout the surgery to maintain BP at $140 / 90-150 / 100 \mathrm{~mm} \mathrm{Hg}$. With an HR of $80-100 /$ minute (Fig. 3). When the BP stood stable for over 30 minutes, the epidural was activated with $6 \mathrm{~mL}$ of $0.25 \%$ bupivacaine + inj. fentanyl $25 \mu \mathrm{g}$. Patient's vitals were stable for the rest of the surgery. Thirty minutes later, the blood sugar was found to be $213 \mathrm{mg} / \mathrm{dL}$ for which DNS was stopped and changed to NS and RL to maintain blood sugar less than $160 \mathrm{mg} / \mathrm{dl}$. The total amount of fluids transfused during surgery was 4 pints of RL, 3 pints of NS, 1 pint of DNS, and $30 \mathrm{~mL}$ of $25 \%$ dextrose.

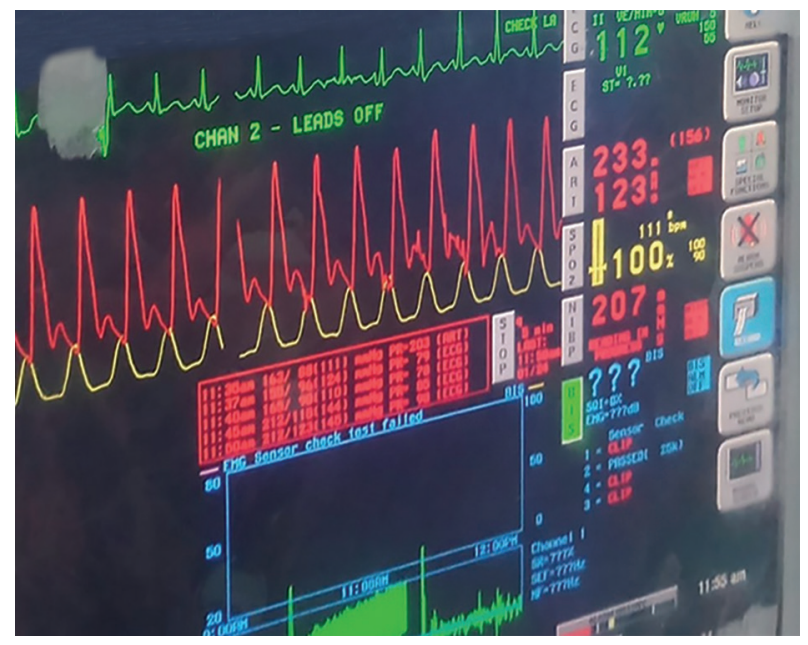

Fig. 1: Hemodynamic changes during tumor handling 


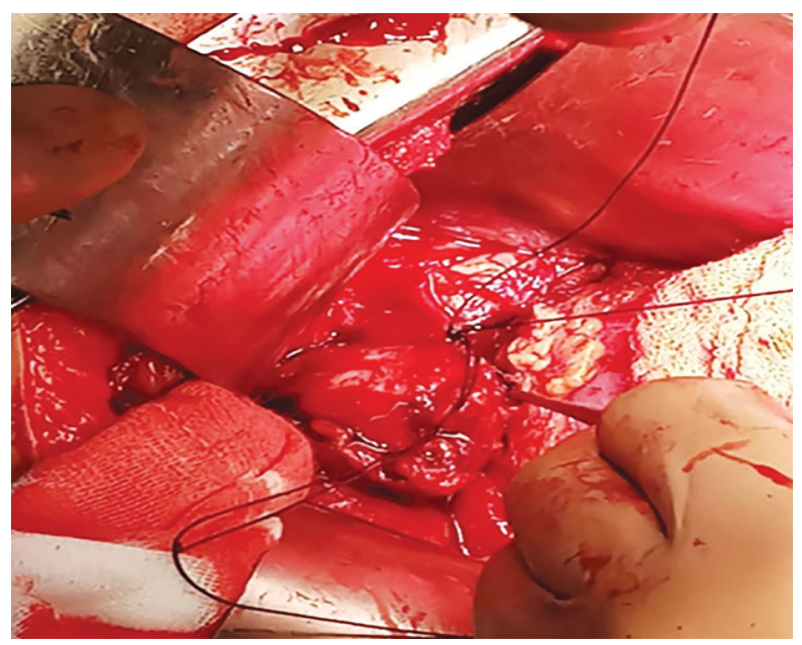

Fig. 2: Intraoperative image of tumor

At the end of the surgery, BP was stable at $136 / 92 \mathrm{~mm} \mathrm{Hg}$, the HR of $92 /$ minute. Arterial blood gas (ABG) report was satisfactory. Inj. esmolol $20 \mathrm{mg}$ was given slow IV before reversal of the neuromuscular blockade with inj. neostigmine $2.5 \mathrm{mg}+$ inj. Glycopyrolate $0.4 \mathrm{mg}$ and the patient was extubated. Inj. noradrenaline was stopped. The patient was shifted to SICU for further monitoring and management for the next 48 hours. One hour postsurgery, BP dropped to $80 / 50 \mathrm{~mm} \mathrm{Hg}$, following which inj. noradrenaline was restarted at $30 \mathrm{mg} /$ hour + mephentermine $6 \mathrm{mg}$ bolus. BP was stabilized at 120/70-140/80 mm Hg. Twenty-four hours postsurgery, BP was $110 / 70 \mathrm{~mm} \mathrm{Hg}$ and the HR was 78/minute, following which noradrenaline was slowly tapered and stopped. The patient was later referred to a physician to estimate the serum cortisol level and for any need of cortisol replacement therapy.

Three days later, BP shoots up to $180 / 110 \mathrm{~mm} \mathrm{Hg}$ and was advised tab. prazosine $2.5 \mathrm{mg}$ and metoprolol $30 \mathrm{mg}$ orally. The patient was discharged on the 6th day after complete stabilization of $B P$ and $H R$.

\section{Case 3}

A 25-year-old primigravida with 20 weeks of gestation came to the antenatal clinic with a history of palpitations and pedal edema. She was found to have gestational diabetes mellitus, on treatment with inj. human mixtard insulin $10 \mathrm{U}-0-20 \mathrm{U}$, and high BP readings ranging between $180 / 100$ and $160 / 100 \mathrm{~mm} \mathrm{Hg}$ on her previous regular antenatal checkups. She was admitted for further evaluation and management in the antenatal ward.

The patient was diagnosed as a case of pregnancy-induced hypertension (PIH) and started on tab. labetalol $100 \mathrm{mg}$ ter in die (TID) and tab nifedipine [sustained release (SR)] $5 \mathrm{mg}$ TID for her hypertension. Endocrinologist's opinion was sought for glycemic control and was started on inj. Human actrapid 10U-10U-8U and inj. Insugen N 0-0-8U. Her BP readings were persistently high, and the dosage of tab. nifedipine was increased to $10 \mathrm{mg}$ bis in die (BD). Since the glycemic control was not adequate, a long-acting insulin inj. Lantus $20 \mathrm{U}$ HS started. Following which her BP readings ranged between 150/90 and 130/100 $\mathrm{mm} \mathrm{Hg}$ and GRBS was $140-160 \mathrm{mg} / \mathrm{dL}$.

On the 10th day of admission, she had a BP of $180 / 100 \mathrm{~mm}$ $\mathrm{Hg}$, she had an episode of generalized tonic-clonic seizures, for which inj. $\mathrm{MgSO}_{4}$ was started according to the Pritchards regimen and inj. labetalol $20 \mathrm{mg}$ IV stat was given. She was monitored continuously. Her BP was stable between 160/100 and 140/100 mm

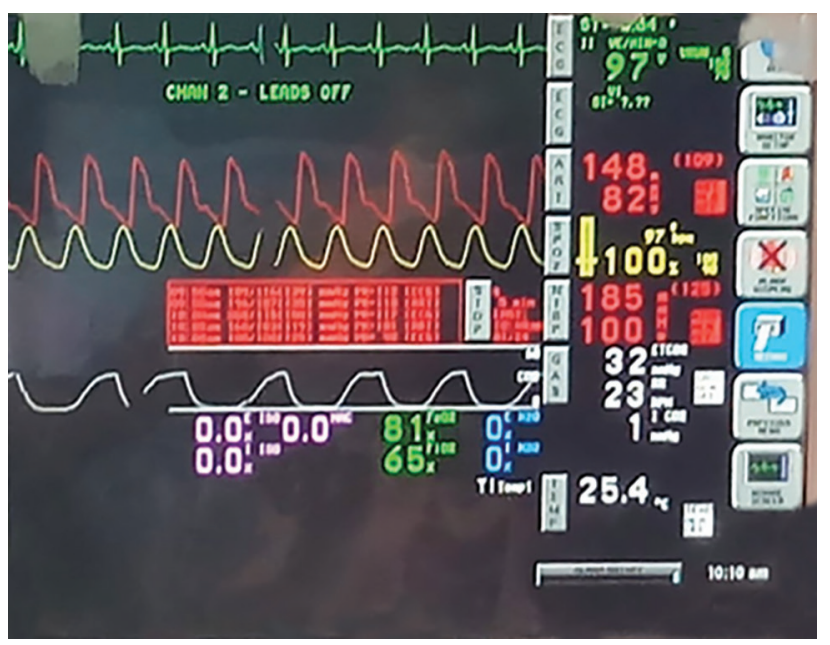

Fig. 3: Hemodynamic maintenance posttumor excision

$\mathrm{Hg}$. The uterus was relaxed, and fetal heart rate (FHR) was good. The patient had another episode of convulsion. Twenty minutes later, her BP was 190/100 mm Hg and her FHR tracings were not satisfactory, hypoglycemia was noted, which was corrected with inj. $25 \%$ dextrose.

The patient was posted for emergency cesarean section. Her body weight was $90 \mathrm{~kg}$ and found to have a short neck, with increased neck circumference, facial puffiness, periorbital edema, and a change in her voice. She had Ronchi for which nebulization was given with budesonide, inj. deriphyllin 1 amp intramuscular (IM) was advised. Her serum potassium level was $2.5 \mathrm{mEq} . / \mathrm{L}$, and the correction was started with inj. $\mathrm{KCl} 20 \mathrm{mEq}$. in $100 \mathrm{~mL}$ of normal saline slow IV.

She was taken up for emergency lower segment cesarean section (LSCS) under high risk, under general anesthesia. Preinduction vitals-BP 200/110 mm Hg; HR 110 bpm; $\mathrm{SpO}_{2} 88 \%$ on room air; $92 \%$ with $6 \mathrm{I}$ of $\mathrm{O}_{2}$. She was preoxygenated and induced with inj. thiopentone $150 \mathrm{mg}$, intubated using inj. scoline $150 \mathrm{mg}$, cuffed endotracheal tube size 6.5, and bilateral air entry checked and fixed at $21 \mathrm{~cm}$. She was maintained with $\mathrm{O}_{2}, 3 \mathrm{~L} /$ minute $+\mathrm{N}_{2} \mathrm{O} 5$ $\mathrm{L} /$ minute + isoflurane $0.6 \%$. Postinduction, her $\mathrm{BP}$ readings ranged between 160/100 and 150/100, HR 100-108 bpm, SpO 2 95\%. After baby's extraction, inj. midazolam $1 \mathrm{mg}$, inj. fentanyl $100 \mathrm{mcg}$ given IV, inj. oxytocin $10 \mathrm{U}$ given IV + 10 units added to IV fluid. In view of airway edema, the patient was planned for elective ventilation and shifted to ICU.

Postoperatively also her BP readings were between 160/100 and $140 / 100 \mathrm{~mm} \mathrm{Hg}$. Physicians advised to put her on tab. labetalol $100 \mathrm{mg} \mathrm{BD}$ and tab. clinidipine $5 \mathrm{mg} \mathrm{BD}$. Repeat serum electrolytes revealed the following: $\mathrm{K}-2.8, \mathrm{Mg}-6.2$, and $\mathrm{Ca}-7.2$ $\mathrm{mEq}$. The correction was initiated accordingly. Pressures were still not under control. Tab. labetalol was stopped and tab. nifidepine (SR) $20 \mathrm{mg}$ was started and tab. clinidipine was continued. She was further evaluated for uncontrolled hypertension. Her 24 hours urine catecholamines and VMA were high and CT scan revealed a right-sided well-defined oval-shaped lesion, mildly hyperdense on T1W and hyperintense on T2W images, measuring $2.3 \times 2.1 \times$ $2.1 \mathrm{~cm}$ adrenal mass. She was diagnosed to have right-sided pheochromocytoma. She was referred to an urologist for further management. She was planned for right adrenalectomy.

Preanesthetic checkup was done. Patient's weight was $86 \mathrm{~kg}$, height $156 \mathrm{~cm}$, and BMI 35.33. Her 24 hours BP monitoring chart 
showed BP 160/100-150/100 mm Hg. Her investigations were within normal limits. The patient was advised to stop all antihypertensives and start on tab. prazosin $10 \mathrm{mg}$ TID for 10 days, following which tab. metoprolol $25 \mathrm{mg}$ BD was added. Throughout this period, her BP ranged between 150/100 and 130/100 $\mathrm{mm} \mathrm{Hg}$.

Preop orders included NPO for 8 hours, tab. alprazolam $2.5 \mathrm{mg}$ for anxiolysis, inj. ranitidine $150 \mathrm{mg}$, and inj. ondansetron $4 \mathrm{mg}$ IV in the morning of surgery, to continue tab. prazosin and tab. metoprolol on the morning of surgery. The patient was planned for laparoscopic adrenalectomy.

\section{Anesthetic Management}

Preanesthetic counseling of the patient and relatives was done and written consent was taken. The operating room was prepared and all drugs required including inotropes, vasodilators, emergency drugs, vasopressors, antiarrhythmics, blood, and blood products were arranged beforehand. Patient's vitals before shifting to OR (BP-180/100, HR-96 beats/minute, FBS-136 mg/dL, and serum electrolytes) were within normal limits. The following monitors were attached: ECG, NIBP, and pulse oxymeter. Two wide bore IV cannulas, 18G, one on each upper limb, were secured. IV fluids started. With the patient in sitting position, under all aseptic precautions, thoracic epidural was secured at the T9-T10 levels. The right radial arterial line secured with a 20-G cannula, for invasive BP monitoring. Baseline arterial BP was 180/100 mm Hg, HR 98 bpm, and $\mathrm{SpO}_{2} \quad 100 \%$. The patient was premedicated with inj. fentanyl $100 \mu \mathrm{g}$ and inj. midazolam $1 \mathrm{mg}$. Injection esmolol $25 \mathrm{mg}$ in $100 \mathrm{~mL}$ normal saline was started slow IV 10 minutes before intubation, to blunt intubation response. BP came down to $160 / 90 \mathrm{~mm} \mathrm{Hg}$. She was induced with inj. propofol $100 \mathrm{mg}$, sevoflurane 1\%, intubated using inj. scoline $100 \mathrm{mg}$, and King vision video-laryngoscope with cuffed endotracheal tube size 7.0. Bilateral air entry checked, and the tube was fixed at $20 \mathrm{~cm}$. She was maintained with $\mathrm{O}_{2}+$ $\mathrm{N}_{2} \mathrm{O}$, and sevoflurane with intermittent doses of inj. vecuronium. Injection paracetamol $1 \mathrm{~g}$ IV was given as multimodal analgesic. Postintubation invasive blood pressure (IBP) 180/100 mm Hg, HR $108 \mathrm{bpm}$, inj. Iabetalol $10 \mathrm{mg}$ was given IV stat. The right subclavian vein was cannulated and the central line was secured. Postinduction vitals at 2 minutes interval were as follows (Table 2):

In view of increasing BP, inj. sodium nitroprusside was started at $1 \mathrm{~mL} /$ hour (1 $\mathrm{mg} / \mathrm{cc}$ ), following which BP dropped to 156/96 mm Hg, HR 99 bpm, and reduced further to $99 / 66 \mathrm{~mm} \mathrm{Hg}$, HR 116 bpm. Secretions were noted in the endotracheal tube. On auscultation, crepitations were heard, in view of intraoperative bronchospasm, nebulization with salbutamol and budesonide, and inj. deriphyllin $200 \mathrm{mg}$ IV and inj. hydrocortisone $100 \mathrm{mg}$ IV were advised. Following which, the chest became clear. The patient was then placed in the left lateral position with adequate soft-tissue padding.

When the surgeons introduced the laparoscopic ports and $\mathrm{CO}_{2}$ insufflation, the BP had an increasing trend from 130/110 to $195 / 107 \mathrm{~mm} \mathrm{Hg}$, and HR 118-110 bpm, inj. labetalol $10 \mathrm{mg}$ stat IV was given, sevoflurane $3 \%$ and inj. sodium nitroprusside continued at $1 \mathrm{~mL} /$ hour. In view of increasing peak airway pressures, suspecting the possibility of pulmonary edema, the patient was put on the pressure control mode of ventilation. BP then reduced to $98 / 74 \mathrm{~mm} \mathrm{Hg}, \mathrm{HR} 103 \mathrm{bpm}$. Inj. SNP stopped, and sevoflurane reduced to $2 \%$. As the surgeons were exploring, a rise in BP was noted 139/104-156/110 mm Hg. Inj. SNP was restarted at $2 \mathrm{~mL} /$ hour and increased to $5 \mathrm{~mL} /$ hour as BP further increased to 180/110 mm Hg (Table 2). Inj. MgSO 1 g IV in 100 mL NS was started slow IV BP then dropped to $100 / 70-110 / 70 \mathrm{~mm} \mathrm{Hg}$. The dose of inj. SNP infusion was reduced to $1 \mathrm{~mL} /$ hour and titrated to maintain BP at 137/80-130/97 $\mathrm{mm} \mathrm{Hg}$. While handling the tumor, the BP rose to $160 / 100-170 / 100 \mathrm{~mm} \mathrm{Hg}, \mathrm{HR} 88 \mathrm{bpm}$, inj. SNP was increased to $2 \mathrm{~mL} /$ hour, and sevoflurane to $3 \%$. Once the tumor was isolated, BP came down to $98 / 64 \mathrm{~mm} \mathrm{Hg}$ and $\mathrm{HR} 90 \mathrm{bpm}$. On complete resection of tumor, BP stood between 117/83 $\mathrm{mm} \mathrm{Hg}$ and 128/92 mm Hg, HR $93 \mathrm{bpm}$, and inj. SNP was stopped (Table 3).

Since the BP was on the increasing trend after 20 minutes (Table 4), inj. SNP was restarted at $3 \mathrm{~mL} /$ hour and subsequently increased to $5 \mathrm{~mL} /$ hour. Inj. labetalol $10 \mathrm{mg}$ IV stat given. The BP then reduced to $140 / 90-126 / 88 \mathrm{~mm} \mathrm{Hg}$ and HR $100 \mathrm{bpm}$. At the end of the surgery, local infiltration with $0.25 \%$ bupivacaine $10 \mathrm{~mL}$ was given at the port sites. Her sugars were within normal limits throughout the procedure.

The patient was planned for extubation. Reversed with inj. neostigmine $2.5 \mathrm{mg}$ + glycopyrrolate $0.4 \mathrm{mg}$. Inj. lignocaine preservative free $3 \mathrm{~mL}$ given 90 seconds before extubation and was extubated. Postextubation vitals-BP 150/100 mm Hg and HR 102 bpm. Epidural top up with $0.0625 \%$ bupivacaine $8 \mathrm{~mL}$ was given for postoperative analgesia.

The patient received 2 pints of RL, 2 pints normal saline, and 1 pint of sterofundin during the surgery. Intraoperative blood loss was around $200 \mathrm{~mL}$. In view of fluctuations in BP, inj. SNP infusion was continued at $1 \mathrm{~mL} /$ hour. The patient was shifted to ICU for observation. Epidural infusion of $0.0625 \%$ bupivacaine $6 \mathrm{~mL} /$ hour, with fentanyl $20 \mu \mathrm{g} /$ hour was continued. In view of persistently high $\mathrm{BP}$, the infusion rate of SNP increased to $1.5 \mathrm{~mL} /$ hour. Tab. prazosin $10 \mathrm{mg}$ was restarted on postop day 1. As the BP was not controlled, tab. metoprolol $25 \mathrm{mg}$ OD and tab. nifedipine $10 \mathrm{mg} \mathrm{BD}$ were started. Inj. SNP infusion and tab.

Table 2: Hemodynamic response to surgical exploration

\begin{tabular}{ll}
\hline$B P(\mathrm{~mm} \mathrm{Hg})$ & $H R(b p m)$ \\
\hline $160 / 90$ & 98 \\
$150 / 90$ & 94 \\
$140 / 90$ & 88 \\
$160 / 100$ & 92 \\
$180 / 100$ & 96 \\
$203 / 107$ & 98 \\
\hline
\end{tabular}

Table 3: Hemodynamics after tumor excision (I)

\begin{tabular}{lc}
\hline$B P(\mathrm{~mm} \mathrm{Hg})$ & $H R(\mathrm{bpm})$ \\
\hline $118 / 82$ & 90 \\
$126 / 76$ & 88 \\
$140 / 88$ & 92 \\
$156 / 90$ & 98 \\
$161 / 102$ & 102 \\
$170 / 100$ & 104 \\
$186 / 110$ & 108 \\
\hline
\end{tabular}

Table 4: Hemodynamics after tumor excision (II)

\begin{tabular}{lc}
\hline$B P(\mathrm{~mm} \mathrm{Hg})$ & $H R(b p m)$ \\
\hline $150 / 100$ & 98 \\
$156 / 90$ & 100 \\
$160 / 100$ & 104 \\
$172 / 110$ & 110 \\
$168 / 98$ & 106 \\
\hline
\end{tabular}


prazosin and epidural infusions were stopped on postop day 3 when all the vitals became stable. BP readings were in the range of $150 / 100-140 / 100 \mathrm{~mm} \mathrm{Hg}$. On postoperative day 5, BP was maintained around 140/90-130/90 mm Hg, tab. nifedipine was stopped and tab. metoprolol $25 \mathrm{mg}$ OD continued.

The histopathological report revealed that the tumor was pheochromocytoma.

\section{Discussion}

Pheochromocytomas, the rare neuroendocrine tumors of adrenal glands, with an incidence of 1 in 1,50,000 to 1 in 2,00,000 population, $0.2-0.6 \%$ in hypertensive patients and an incidence of $50 \%$ of these tumors being extra-adrenal, called as paragangliomas, pose very significant challenges to anesthetists when they are posted for excision, especially when they are undiagnosed. ${ }^{1-3}$ The anesthetic management of these tumor excisions varies with the preoperative hemodynamic stability, surgical approach, and perioperative hemodynamic instability encountered by the anesthetist. They may present with life-threatening situations and hypertensive crisis, especially when they are undiagnosed, with a mortality of up to $80 \%$. $^{3}$

Thorough preoperative investigation and hemodynamic stabilization with appropriate alpha and beta blockers is an absolute necessary before taking up for surgery.

Intraoperative fluctuations in BP and HR may be extreme and put the anesthetist on tantrum forcing him/her to be well prepared with all the cardiac drugs ready to use, take quick and appropriate decision to control these hemodynamic changes to prevent lifethreatening complications. ${ }^{6-13}$

As seen with the cases presented here, pheochromocytoma can present as mild dull aching pain in the groin, lumbar region, or no pain. A mere suspicion of pheochromocytoma in uncontrolled hypertension with conventional antihypertensive agents and thorough investigation for serum cortisol, VMA, and urinary cortisone level can confirm the diagnosis.

In pregnant ladies, the diagnosis may be missed, suspecting the variations in the $\mathrm{BP}$ to $\mathrm{PIH}^{14,15}$

Efficient perioperative monitoring and management with proper inotropes or IV fluids infusion with NS/RL to fill the expanded intravascular space in a nonfunctioning uncomplicated pheochromocytoma keeps the variations in cardiac parameters within the acceptable range and prevents any major complications as we did in our Case $1 .^{2}$

\section{Conclusion}

Suspicion of pheochromocytoma should be kept in mind in all hypertensive patients who are not responding to conventional antihypertensive drugs and should be thoroughly investigated. Once the diagnosis is confirmed, all necessary precautions should be taken to bring the BP under control before taking up for adrenalectomy. All cardiac drugs and defibrillator should be kept ready in the OT for efficient management of any crisis encountered during the surgery.

\section{References}

1. Golden SH, Robinson KA, et al. Clinical review: Prevalence and incidence of endocrine and metabolic disorders in the United States: A comprehensive review. J Cilin Endocrine Metab 2009;94:1853-1878. DOI: 10.1210/jc.2008-2291.

2. Connor D, Boumphey S. Perioprative care of Pheochromocytoma. BJA Education 2016;16(5):153-158. DOI: 10.1093/bjaed/mkv033.

3. Myklejord DJ. Undiagnosed pheochromocytoma: The anesthetist nightmare. Clin Med Res 2004;2:59-62. DOI: 10.3121/cmr.2.1.59.

4. Roizen MF, Horrigan RW, et al. A prospective randomized trialof four anesthetic techniques for resection of pheochromocytoma. Anesthesiology 1982;57:A43. DOI: 10.1097/00000542-19820900100043.

5. Roizen MF, Schreider BD. Anesthesia for patients with pheochromocytoma. Anesthesiol Clin North America 1987;5:269-275.

6. Mazza A, Armigliato M, et al. Anti-hypertensive treatment in pheochromocytoma and paragangloma: Current management and therapeutic features. Endocrine 2014;45:469-478. DOI: 10.1007/ s12020-013-0007-y.

7. Pacak K. Preoperative management of pheochromocytoma patient. J Clin Endocrinol Metab 2007;92:4069-4079. DOI: 10.1210/jc.2007-1720.

8. Subramanian R. Pheochromocytoma - current concepts in diagnosis and management trends. Anesth Crit Care 2011;1:104-110.

9. Fishbein I, Orlowski R, et al. Pheochromocytoma/paragangloma: Review of perioperative management of blood pressur and update of genetic mutations associated with pheochromocytoma. J Clin Hpertins (Greenwich) 2013;15:428-434. DOI: 10.1111/jch.12084.

10. Hull CJ. Pheochromocytoma. Diagnosis, preoperative preparation and anaesthetic management. Br J Anaesth 1986;58:1453-1468. DOI: 10.1093/bja/58.12.1453.

11. Houston M. The role of Magnesium in hypertension and cardiovascular disease. J Clin Hypertens (Greenwich) 2011;13:843-847. DOI: 10.1111/j.1751-7176.2011.00538.x.

12. Roth JV. Use of vasopressin bolus and infusion to treat catecholamine-resistant hypotension during pheochromocytoma resection. Anesthesiology 2007;106:883-884. DOI: 10.1097/01. anes.0000264786.22478.9e.

13. Mellon MJ, Sundaram CP. Laparoscopic adrenalectomy for pheochromocytoma versus other surgical indications. JSLS 2008;12:380-384.

14. Harrington JL, Farley DR, et al. Adrenal tumors and pregnancy. World J Surg 1999;23:182-186. DOI: 10.1007/PL00013159.

15. Sarathi V, Lila AR, et al. Pheochromocytoma and pregnancy: a rare but dangerous combination. Endocr Pract 2010;16:300-309. DOI: 10.4158/EP09191.RA. 